\title{
Distance Learning Courses
}

Célia Soares, Nelson Lima

CEB-Biological Engineering Centre, Micoteca da Universidade do Minho, University of Minho, Campus of Gualtar, Braga, Portugal

In a world of new technologies the concept of Distance Learning or Distance Education has known its own evolution. As Tony Bates puts it: "Because of the development of information and communications technologies, the nature of knowledge is changing, and that affects not only what we teach, but also how we teach" (1).

For this reason Universities are expanding its knowledge diffusion through e-learning to serve larger populations of students or students with expectations for modern technology and a modernized education experience. It also has the potential to make less commonly taught subjects available to more students. This requires a different approach in terms of course planning, design, delivery and communications. The format will depend on the purpose of the online course.

The concept of Distance Learning has its advantages and disadvantages but, overall, it enables students to take responsibility for their own learning, to be flexible and adaptable in developing new knowledge and skills. Nevertheless, self-motivation and the developing of persistent and self-directing working skills are highly needed. As for the teachers, they need to develop and use new teaching methodologies and styles, by managing learning strategies, supporting students, facilitating debate at a distance and disseminating information and views.

\section{References}

(1)Teaching in a Digital Age: Guidelines for Designing Teaching and Learning. A.W. Bates Vancouver BC: Tony Bates Associates Ltd, 2015. 